\title{
Acesso legal ao conhecimento tradicional associado à biodiversidade no Brasil: Novas perspectivas nacionais
}

\author{
Legal access to traditional knowledge associated with biodiversity in Brazil: New national \\ perspectives \\ Acceso legal al conocimiento tradicional asociado a la biodiversidad en Brasil: Nuevas perspectivas \\ nacionales
}

\author{
André Luiz Gomes de Souza \\ ORCID: https://orcid.org/0000-0002-6807-8774 \\ Universidade Federal de Sergipe, Brasil \\ E-mail:andre.luizgomes@yahoo.com.br \\ Gabriel Francisco da Silva \\ ORCID: https://orcid.org/0000-0002-9622-2518 \\ Universidade Federal de Sergipe, Brasil \\ E-mail: gabriel@ufs.br
}

\begin{abstract}
Resumo
Desde a década de 1980 tem sido verificado acentuado crescimento do número de aplicações tecnológicas de recursos genéticos da biodiversidade baseadas em Conhecimentos Tradicionais Associados (CTA) na busca por soluções aos problemas enfrentados pela humanidade. Decorrentemente, desde o início da década de 1990 o CTA vem sendo objeto de discussão acerca do seu uso legal. Assim, diferentes diretrizes internacionais e instrumentos jurídicos nacionais têm surgido no sentido de estabelecer condições apropriadas ao acesso e exploração econômica legais e à repartição justa dos benefícios advindos. O estabelecimento de tais condições tornou-se relevante para o delineamento de estratégias de desenvolvimento de países megadiversos e as discussões perpassam pela importância da preservação da biodiversidade, exploração sustentável, impactos culturais e apropriações indevidas. Neste contexto, o objetivo desta pesquisa foi analisar indicadores oficiais de acesso legal ao CTA a fim de explicitar as expectativas nacionais acerca do das efetividades das políticas públicas relacionadas ao tema. O presente estudo se caracteriza por ser uma pesquisa exploratória, documental, quantitativa, histórico e longitudinal. Analisaram-se documentos e dados oficiais divulgados pelo órgão responsável pela regulamentação e deliberação do acesso legal ao CTA no Brasil durante o período de 2002 a 2020. Os resultados demonstram relevante crescimento do número de registros de atividades científicas e tecnológicas com acesso ao CTA regularizadas no Brasil, o que foi impulsionado pela implementação do SisGen. Porém, em contrapartida, a transparência de informações se encontra prejudicada em virtude de indisponibilização de informações que eram divulgadas pelo CGEN durante vigência da MP 2.186/2001.
\end{abstract}

Palavras-chave: Sociobiodiversidade; Biotecnologia; Propriedade intelectual.

\begin{abstract}
Since the 1980s, there is an increase in the availability of technological applications of genetic resources from biodiversity based on Associated Traditional Knowledge (ATK). That happens to try to find solutions to the problems faced by humanity. Since the beginning of the 1990s, ATK has been subject to a discussion about its legal use. Different international guidelines and national juridical instruments have emerged to establish appropriate conditions for lawful access, economic exploitation, and fair sharing of benefits. The establishment of such conditions has become relevant for the design of development strategies of megadiverse countries. The discussions also go through the importance of preserving biodiversity, sustainable exploitation, cultural impacts, and undue appropriations. Our objective was to analyze official indicators of legitimate access to ATK to explain national expectations about how its public policies are effective. The present study is characterized by being an exploratory, documentary, quantitative, historical and longitudinal research. Official documents and data published by the body responsible for the regulation and deliberation of legal access to CTA in Brazil during the period from 2002 to 2020 were analyzed. The results demonstrate a significant growth in the number of records of scientific and technological activities with access to CTA regularized in the period. Brazil, which was driven by the implementation of SisGen. However, on the other hand, the transparency of information is impaired due to the unavailability of information that was disclosed by CGEN during the term of MP 2,186 / 2001.
\end{abstract}

Keywords: Sociobiodiversity; Biotechnology; Intellectual property. 


\begin{abstract}
Resumen
Desde la década de los 80, se ha producido un marcado incremento en el número de aplicaciones tecnológicas de los recursos genéticos de la biodiversidad basadas en los Conocimientos Tradicionales Asociados (CTA) en la búsqueda de soluciones a los problemas que enfrenta la humanidad. Desde principios de la década de 1990, los CTA han sido objeto de discusión sobre su uso legal. Han surgido diferentes directrices internacionales e instrumentos jurídicos nacionales con el fin de establecer las condiciones adecuadas para el acceso, la explotación económica legal, además de la distribución justa de los beneficios. El establecimiento de tales condiciones ha cobrado relevancia para el diseño de estrategias de desarrollo de países megadiversos y las discusiones pasan por la importancia de preservar la biodiversidad, la explotación sostenible, los impactos culturales y las apropiaciones indebidas. En este escenario, el objetivo de esta investigación fue analizar los indicadores oficiales de acceso legal a los CTA con el fin de explicar las expectativas nacionales sobre la efectividad de las políticas públicas relacionadas con el tema. El presente estudio se caracteriza por ser una investigación exploratoria, documental, cuantitativa, histórica y longitudinal. Se analizaron documentos oficiales y datos publicados por el organismo responsable de la regulación y deliberación del acceso legal a la CTA en Brasil durante el período 2002 a 2020. Los resultados demuestran un crecimiento significativo en el número de registros de actividades científicas y tecnológicas con acceso a CTA regularizada en el período Brasil, que fue impulsada por la implementación de SisGen. Sin embargo, por otro lado, la transparencia de la información se ve afectada por la indisponibilidad de la información que fue divulgada por CGEN durante el plazo de la MP 2.186/ 2001.
\end{abstract}

Palabras clave: Sociobiodiversidad; Biotecnología; Propiedad intelectual.

\title{
1. Introdução
}

O termo Conhecimento Tradicional Associado (CTA) faz referência aos conhecimentos manifestados nos saberes e afazeres de povos indígenas e comunidades tradicionais que estão relacionados ao uso de recursos genéticos da biodiversidade em diferentes contextos, como agrícola, alimentício, medicinal e tecnológico. Contudo, o CTA não pode ser considerado um conhecimento antepassado por ser tradicional, pois a tradicionalidade se refere ao contexto sociocultural em que o mesmo se cria e se difunde. Desse modo, ele não é estático e sim, dinâmico, e está em constante criação, desenvolvimento e inovação.

O cenário internacional vem apresentando, desde a década de 1980, acentuado crescimento do número de aplicações tecnológicas de recursos genéticos da biodiversidade (Kaplan \& Figueiredo, 2006). Essa realidade tem incentivado estudos em diferentes áreas do conhecimento, tanto que, atualmente, são observados na literatura científica alguns ramos da pesquisa interessados em identificar o CTA de povos e comunidades tradicionais, enquanto que outros estão focados em comprovar cientificamente as suas potencialidades (Souza, 2019).

Os recursos da biodiversidade e o CTA são considerados relevantes para negócios e indústrias globais por dois fatores. Primeiramente, porque as antigas tecnologias químicas estão falhando, tanto na agricultura como na saúde. Em seguida, porque a acumulação de capital está conduzindo o lançamento de novas tecnologias, como a biotecnologia, para o aumento do controle sobre mercados e recursos (Shiva, 2005).

Assim, o CTA vem se consolidando como importante fonte de informações aplicadas por centros de pesquisa e indústrias farmacêuticas, biotecnológicas, agrícolas e químicas (Alier, 2012), e adquire particular importância para estes setores industriais por possibilitar a identificação de princípios ativos de biomoléculas ou características funcionais celulares (Santilli, 2005).

No Brasil, atualmente, são mais de 650 espécies com valor econômico na Amazônia Legal Brasileira (TEEB, 2012), e ao menos 245 espécies da flora brasileira que são base de produtos cosméticos e farmacêuticos, das quais ao menos 36 espécies botânicas nativas possuem registro oficial de produto fitoterápico (Joly, 2018).

Devido ao contexto apresentado relacionado ao crescente interesse em torno do uso industrial de CTA é que, considerável percentual de países megadiversos em recursos genéticos tem sido afetado negativamente, seja em virtude de impactos ambientais advindos de sistemas de produção ou do extrativismo insustentável dos recursos florestais, como também pelas perdas de potenciais geradores de divisas no âmbito do comércio internacional.

Assim, desde o início da década de 1990 o CTA vem sendo objeto de discussão acerca do seu uso legal e apropriação 
indevida. Diferentes diretrizes internacionais e instrumentos jurídicos nacionais têm surgido no sentido de estabelecer condições apropriadas ao acesso e exploração econômica legais e à repartição justa e equitativa dos benefícios advindos. O estabelecimento de tais condições tornou-se relevante para o delineamento de estratégias de desenvolvimento para os países megadiversos.

Essas discussões perpassam pela importância da preservação da biodiversidade, pela preocupação com os impactos ambientais advindos das explorações econômicas dos recursos naturais e pela garantia da proteção e combate à apropriação indevida de CTA com grandes potenciais de geração de divisas para países em desenvolvimento. Todos esses fatores estão associados ao fato da biodiversidade e do CTA haverem se tornado, no final do século 20, uma das mais importantes e promissoras fontes de soluções e matérias primas para grandes corporações internacionais que representam parcelas significativas dos mercados de produtos medicinais, cosméticos e químico.

Embora a estruturação de diretrizes internacionais e aparatos legais nacionais representem avanços relacionados ao tema, no Brasil, não atingiram seus objetivos e inúmeros casos de acesso indevido ao Patrimônio Genético Nacional (PGN) e ao CTA continuaram ocorrendo. Essa realidade é apresentada nos registros das Operações Novos Rumos I e Novos Rumos II, realizadas pelo Instituto Brasileiro do Meio Ambiente e dos Recursos Naturais Renováveis (IBAMA) nos anos 2010 e 2012, nas quais estiveram em questão aplicações do PGN e do CTA em produtos medicinais e cosméticos comercializados em nível internacional (Souza, 2019).

A combinação de uma legislação nacional de regulamentação do acesso ao PGN e ao CTA subjetiva, com as distintas expectativas quanto às formas e finalidades de exploração do PGN e do CTA apresentadas pelos grupos sociais envolvidos, ambos inseridos em um cenário global que infere alto nível de interesse por suas explorações econômicas para o desenvolvimento de novas tecnologias foram elementos que compuseram o quadro que culminou com a promulgação da Lei 13.123 de 2015, o Novo Marco Legal da Biodiversidade Brasileira, que começou a apesentar seus resultados a partir do ano de 2019.

Neste sentido, esta pesquisa teve o objetivo de analisar os indicadores oficiais de acesso legal ao CTA no Brasil a fim de explicitar as expectativas nacionais acerca da efetividade das políticas públicas relacionadas ao tema.

\section{Diretrizes Internacionais de Acesso Legal ao CTA}

As primeiras diretrizes internacionais que tratam de questões atinentes à proteção, ao acesso legal e às repartições de benefícios advindos da exploração do CTA são apresentadas na Convenção sobre a Diversidade Biológica - CDB, aprovada na Conferência das Nações Unidas sobre o Meio Ambiente e o Desenvolvimento no ano de 1992. Posteriormente, no ano de 2002, a aprovação das Diretrizes de Bonn sobre o Acesso aos Recursos Genéticos e Repartição Justa e Equitativo dos Benefícios derivados de sua Utilização (Guia de Boas Condutos de Bonn) possibilitou a apresentação de um documento de orientação internacional com recomendações e alternativas a serem adotadas a fim de garantir a repartição justa e equitativa dos benefícios advindos da exploração econômica de CTA. Em seguida, no ano de 2011, noventa e uma nações assumiram o compromisso da implementação do Guia de Boas Condutos de Bonn quando firmaram a aprovação do Protocolo de Nagoya sobre Acesso a Recursos Genéticos e da Repartição Justa e Equitativa de Benefícios derivados da sua Utilização, que entrou em vigor no ano de 2014 (Souza, 2019).

Essas diretrizes internacionais reconhecem a necessidade da garantia de direitos das sociedades tradicionais ao consentimento livre, prévio e informado e às repartições de benefícios advindos dos usos e explorações do CTA junto aos povos e comunidades tradicionais provedores e detentores desses conhecimentos.

No entanto, o sistema mundial de propriedade intelectual, regulado pelo Acordo TRIPS (em inglês: Agreement on Trade-Related Aspects of Intellectual Property Rights, em português: Acordo sobre Aspectos dos Direitos de Propriedade 
Intelectual Relacionados ao Comércio), que é o tratado internacional integrante do conjunto de acordos assinados em 1994 que encerrou a Rodada Uruguai e criou o Organização Mundial do Comércio (OMC), ainda não desenvolveu consentimento acerca das diretrizes relacionadas à proteção do direitos de propriedade intelectual e exploração econômica de CTA

Bertogna e Cibim (2006) enfatizam que o CTA não é abarcado pelas legislações de proteção dos direitos de propriedade intelectual por não satisfazerem os níveis de inventividade e os critérios básicos de reprodutibilidade industrial imediata exigidos para a concessão de Cartas Patente. Ademais, muitos CTA são utilizados cotidianamente pela sociedade, pois foram transmitidos oralmente através de diversas gerações, sem documentação produzida, logo, esses conhecimentos não são absolutamente novos, e assim também não preenchem o terceiro requisito necessário à concessão de Carta Patente, a novidade.

Apesar da falta de um instrumento jurídico internacional no âmbito da propriedade intelectual que regule o acesso, proteção e repartição de benefícios referentes ao uso do CTA, a Organização Mundial de Propriedade Intelectual (OMPI) considera que as inovações baseadas em CTA podem receber proteção de carta patente, registro de marca e de indicações geográficas ou também na forma de segredo comercial ou informação confidencial. Porém, o CTA, propriamente dito, o qual possui raízes antigas e são transmitidos na oralidade das pessoas, não são protegidos pelos sistemas convencionais de propriedade intelectual (OMPI, 2014).

Desde 2001, o Comitê Internacional da OMPI sobre Propriedade Intelectual e Recursos Genéticos, Conhecimentos Tradicionais e Folclore (CIG) vem realizando negociações com o objetivo de alcançar um acordo sobre um instrumento jurídico internacional (ou vários) que assegure a efetiva proteção do CTA e das expressões culturais tradicionais, com abordagem dos aspetos da propriedade intelectual relativos aos recursos genéticos e às repartições de benefícios que estes podem gerar (OMPI, 2014). Várias sessões CIG são realizadas anualmente com mesas redondas e apresentações de trabalhos científicos relacionados aos CTA de povos indígenas e comunidades tradicionais. Todavia, até o ano de 2020, o CIG ainda não conseguiu atingir consentimento acerca de diretrizes internacionais de proteção e uso do CTA no âmbito sistema internacional de propriedade intelectual.

\section{Legislação Nacional de Acesso ao CTA no Brasil}

O Estado Brasileiro assumiu obrigações de estabelecer regras para o acesso e exploração econômica legais do PGN e do CTA de povos indígenas e comunidades tradicionais do Brasil tornando-se signatário da CDB. Este documento foi assinado na Conferência das Nações Unidas sobre o Meio Ambiente e o Desenvolvimento no ano de 1992, aprovado pelo Congresso Nacional por meio do Decreto Legislativo ${ }^{\circ}$ 2, de 3 de fevereiro de 1994 e promulgado pelo Decreto Presidencial $\mathrm{n}^{\circ} 2.519$, de 16 de março de 1998.

No entanto, somente após conflito de interesse relacionado ao uso e exploração econômica do PGN ocorrido no ano de 2000, que o Estado Brasileiro promulgou a Medida Provisória no 2.186-16 de 23 de agosto de 2001 (MP 2.186/2001) e regulamentou as atividades com acesso ao PGN e ao CTA para fins de pesquisa científica, bioprospecção e desenvolvimento tecnológico, e os contratos de uso do patrimônio genético e repartições de benefícios (CURB) advindos da exploração econômica de PGN e/ou CTA (Brasil, 2001). Assim, interessados como empresas privadas, centros de pesquisa e universidades, sejam nacionais ou internacionais, interessados em acessá-los e aplicá-los no desenvolvimento das suas atividades passaram a ser obrigados a cumprir requisitos e procedimentos legais. Quando houvesse perspectiva de uso comercial, o acesso ao CTA só poderia ocorrer após assinatura de Contrato de Utilização do Patrimônio Genético e de Repartição de Benefícios (CURB).

A MP 2.186/2001 foi criada no ano de 2000 e reeditada por 15 vezes consecutivas em 2001, porém, após aprovação da Emenda Constitucional no 32/2001, foi mantida como Medida Permanente até o ano de 2015, quando foi promulgada a Lei 


\subsection{3 de 20 de maio de 2015.}

A MP 2.186/2001 passou a regulamentar os bens, os direitos e as obrigações relativos: I - ao acesso a componente do PGN existente no território nacional, na plataforma continental e na zona econômica exclusiva para fins de pesquisa científica, desenvolvimento tecnológico ou bioprospecção; II - ao acesso ao CTA , relevante a conservação da diversidade biológica, a integridade do PGN do país e a utilização de seus componentes; III - à repartição justa e equitativa dos benefícios derivados da exploração de componente do PGN e do CTA; e IV - ao acesso e à transferência de tecnologia relevante para a conservação e a utilização da diversidade biológica (Brasil, 2001).

Oficialmente, durante a vigência da MP 2.186/2001, o Estado Brasileiro adotou enquanto conceito de CTA a "informação ou prática individual ou coletiva de comunidade indígena ou de comunidade local, com valor real ou potencial, associada ao patrimônio genético", ao tempo que passou a considerar que o acesso ao CTA referia-se à "obtenção de informação sobre conhecimento ou prática individual ou coletiva, associada ao patrimônio genético, de comunidade indígena ou de comunidade local, para fins de pesquisa científica, desenvolvimento tecnológico ou bioprospecção, visando sua aplicação industrial ou de outra natureza" (Ibidem).

MP 2.186/2001 previa que a autorização de acesso legal dar-se-ia após as seguintes possibilidades de anuência prévia: I - da comunidade indígena envolvida, ouvido o órgão indigenista oficial, quando o acesso ocorrer em terra indígena; II - do órgão competente, quando o acesso ocorrer em área protegida; III - do titular de área privada, quando o acesso nela ocorrer; IV - do Conselho de Defesa Nacional, quando o acesso se der em área indispensável à segurança nacional; V - da autoridade marítima, quando o acesso se der em águas jurisdicionais brasileiras, na plataforma continental e na zona econômica exclusiva (Ibidem).

A MP 2.186/2001 previa que os benefícios resultantes da exploração econômica de produto ou processo desenvolvido a partir de amostra de PGN e CTA deveriam ser repartidos, de forma justa e equitativa, entre as partes contratantes. Porém, a MP 2.186/2001 não estabelecia valores fixos ou percentuais que deveriam ser repartidos juntos aos provedores de PGN ou CTA. Entretanto, estabelecia que os benefícios decorrentes da exploração econômica de amostra do PGN ou de CTA poderiam constituir-se, dentre outros, de: divisão de lucros; pagamento de royalties; acesso e transferência de tecnologias; licenciamento, livre de ônus, de produtos e processos; e capacitação de recursos humanos.

Porém, no Brasil, com propósito de mitigar os conflitos relacionados com a subjetividade e pouca efetividade da MP 2.186/2001, a Presidência da República do Estado Brasileiro encaminhou no início do ano de 2015, em caráter de urgência constitucional, para o Congresso Nacional o Projeto de Lei $\mathrm{n}^{\circ}$ 7.735/2014. Por ter sido enviado em caráter de urgência constitucional, e assim trancar as pautas da Câmara dos Deputados do Congresso Nacional, o Projeto de Lei no 7.735/2014 foi aprovada, tanto no Câmara dos Deputados quanto no Senado Federal em curtos períodos. Nesse contexto foi promulgada a Lei 13.123, de 20 de maio de 2015 (Lei 13.123/2015), a qual revogou a MP 2.186/2001, e que em seguida foi regulamentado pelo Decreto Presidencial no 8.772 , de 11 de maio de 2016.

Dentre as alterações proporcionadas pela Lei 13.123/2015, destaca-se a simplificação do processo de autorização de acesso legal ao PGN e ao CTA através da informatização dos procedimentos administrativos com a implementação do SisGen (Sistema Nacional de Gestão do Patrimônio Genético e do Conhecimento Tradicional Associado); o estabelecimento da repartição de benefícios em intervalos percentuais entre $0,1 \%$ e 1,0\% somente em caso de exploração comercial; a divisão do CTA em duas categorias (origem identificável e origem não identificável); a alteração da composição do Conselho Nacional de Gestão do Patrimônio Genético (CGEN) incorporando entidades empresariais e representações da sociedade civil; e a criação do Fundo Nacional para a Repartição de Benefícios (FNRB) (Brasil, 2015a). Contudo, a sistematização dos dados oficiais relacionados ao acesso legal e ilegal ao CTA, à exploração econômica de CTA e às repartições de benefícios de suas explorações econômicas continuou latente no Estado Brasileiro. 
Após a promulgação da Lei 13.123/2015, o Estado Brasileiro apresentou um avanço no conceito de CTA e passou a considerar os agricultores tradicionais enquanto integrantes do universo de povos e comunidades tradicionais do Brasil, e passou a definir CTA como: "informação ou prática de população indígena, comunidade tradicional ou agricultor tradicional sobre as propriedades ou usos diretos ou indiretos associada ao patrimônio genético".

A Lei 13.123/2015 também passou a considerar no conceito de acesso ao CTA que este poderia ser realizado com acesso à fontes secundárias, e assim passou a denominá-lo como a "pesquisa ou desenvolvimento tecnológico realizado sobre conhecimento tradicional associado ao patrimônio genético que possibilite ou facilite o acesso ao patrimônio genético, ainda que obtido de fontes secundárias tais como feiras, publicações, inventários, filmes, artigos científicos, cadastros e outras formas de sistematização e registro de conhecimentos tradicionais associados" (Ibidem).

Atualmente, por meio do SisGen são realizados todos os cadastros, autorizações, notificações de produtos acabados ou materiais reprodutivos, e obtenção dos respectivos comprovantes e atestados de regularidade. O Decreto $\mathrm{n}^{\circ}$ 8.772/2016 estabelece que o cadastramento deverá ser realizado previamente às pesquisas; à remessa; ao requerimento de qualquer direito de propriedade intelectual; à comercialização do produto intermediário; à divulgação dos resultados, finais ou parciais, em meios científicos ou de comunicação; ou à notificação de produto acabado ou material reprodutivo desenvolvido em decorrência do acesso (Ibidem).

\section{Metodologia}

O presente estudo se caracteriza por ser uma pesquisa exploratória, documental, quantitativa, histórica e longitudinal. Analisaram-se documentos oficiais relacionados ao acesso legal ao CTA divulgados pelo órgão que regulamenta e delibera o acesso legal ao PGN e ao CTA e os acordos de repartições de benefícios no Brasil, tanto durante o período de vigência da MP 2.186/2001 quanto durante o período de vigência da Lei 13.123/2015.

O método histórico de recorte longitudinal baseado em documentos oficiais consiste em coletar informações de vários documentos que permitam compreender as mudanças ocorridas na sociedade e suas instituições ao longo da história a fim de detectar suas implicações na atualidade influenciada pelo contexto social, cultural e econômico particular de cada época. Por sua vez, a adoção do enfoque quantitativo proporciona uma lógica de análise sistematizada unindo diferentes variáveis que auxiliam nas comprovações de veracidade de hipóteses introduzindo-se técnicas e instrumentos de mensuração que visam assegurar a objetividade do conhecimento, a coerência, o rigor - no sentido da exatidão, e a relevância do saber científico (Lakatos \& Marconi, 2003; Rampazzo \& Corrêa, 2008).

Desse modo, analisaram-se dados registrados nos Relatórios de Atividades Anuais do CGEN e nas Deliberações de Aceso ao CTA divulgados pelo CGEN durante a vigência da MP 2.186/2001. Analisaram-se dados quantitativos relacionados à série histórica, tipo de interessados (Empresa, Universidade, Centro de Pesquisa Estatal ou ONG), tipo de autorização (Pesquisa Científica, Bioprospeç̧ão e Desenvolvimento Tecnológico), Estado da Federação, local de acesso (Unidade de Conservação ou Território Indígena), matriz do PGN acessada, e povos e comunidades tradicionais provedores de CTA (Brasil/MMA, 2015b, 2016b).

Posteriormente, analisaram-se dados quantitativos disponibilizados nos cadastros de atividades com acesso ao PGN e/ou CTA registrados durante o período de vigência da Lei 13.123/2015 divulgados via plataforma eletrônica SisGen. Analisaram-se dados relacionados ao tipo de interessados (Pessoa Física, Empresa Privada, Universidade, Centro de Pesquisa Estatal, Instituto Federal de Ciência e Tecnologia, Autarquia Pública ou ONG) e ao objeto de acesso (Patrimônio Genético, Conhecimento Tradicional e acesso mútuo ao Patrimônio Genético e Conhecimento Tradicional Associado) (Brasil/MMA, 2020). 


\section{Resultados e Discussões}

\subsection{Análise dos relatórios anuais de atividades do CGEN durante vigência da MP 2.186/2001 (2002 - 2014)}

As análises dos Relatórios Anuais de Atividades do CGEN, divulgados durante vigência da MP 2.186/2001, resultou na identificação de um total de 669 Solicitações de Autorização Acesso e/ou Remessa do PGN e/ou CTA e 303 Autorizações Concedidas. Desse modo, o percentual de 45,29\% dos processos autuados pelo CGEN durante este período analisado foi oficialmente autorizado para implementações, considerando as atividades de Pesquisa Científica, Bioprospecção e Desenvolvimento Tecnológico (Figura 1).

A série histórica dos registros das Solicitações de Autorização Acesso e Autorizações Concedidas apresenta oscilações em seus somatórios anuais ao longo do período analisado, porém, com tendência positiva (Figura 1), que pode estar relacionada ao crescimento da exploração econômica do PGN e do CTA.

Figura 1. Série histórica dos registros oficiais brasileiros de Solicitações de Autorização de Acesso e de Autorizações Concedidas relacionadas ao acesso ao PGN e ao CTA no período de 2002 a 2014 (unid.)

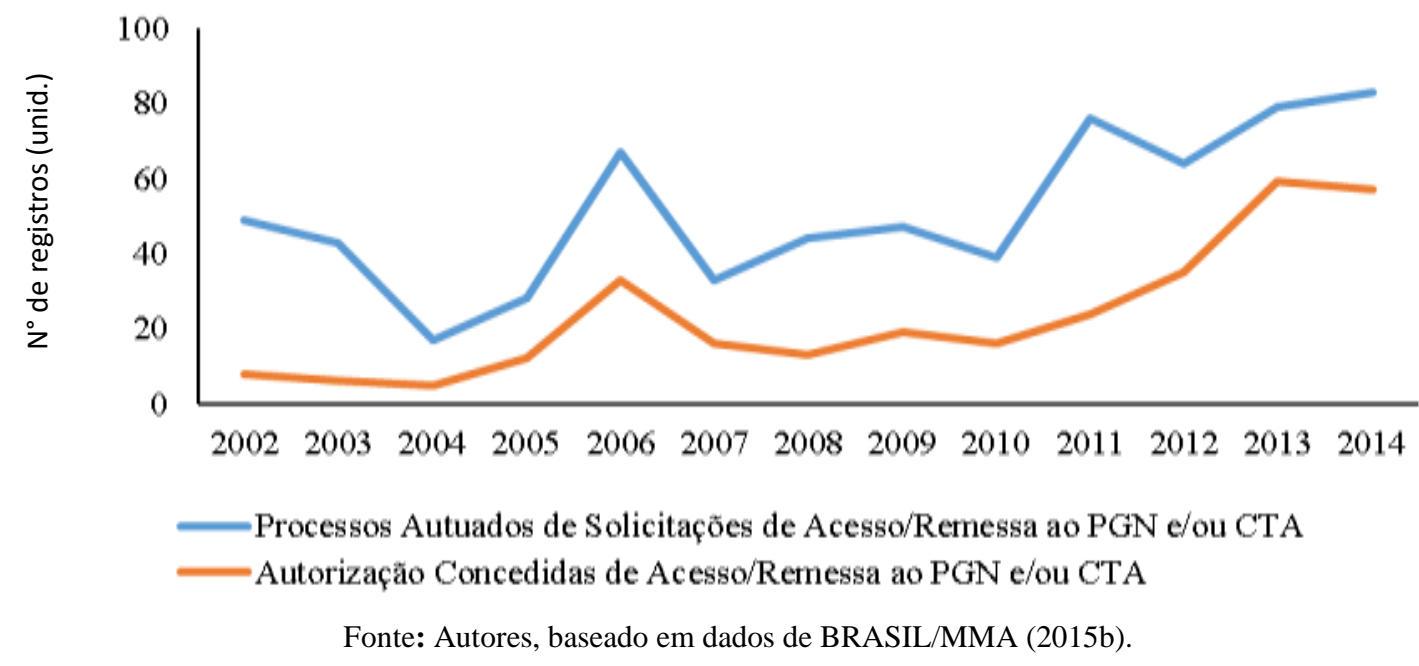

As elevações nos registros observadas a partir do ano de 2005 estão relacionadas com a promulgação do Decreto 5.459/2005 (Brasil, 2005), que foi o primeiro instrumento jurídico de regulamentação das sanções aplicáveis às condutas e atividades lesivas ao PGN ou ao CTA previstas na MP 2.186/2001.

A edição do Decreto n. ${ }^{\circ} 5.459 / 2005$, por ter sido ferramenta adequada à penalização de infratores contra as normas atinentes ao PGN e ao CTA, teve o poder de induzir um número crescente de empresas brasileiras usuárias de informações do PGN a se regularizarem junto ao CGEN. Algumas visavam obter autorização para acesso futuro, conforme a norma, porém, outras o fizeram com o objetivo de regularizar acessos que vinham sendo praticados ilegalmente (Barbosa, 2017).

Por sua vez, as elevações observadas a partir do ano de 2011 foram consequência das autuações de advertências e multas aplicadas pelas Operações Novos Rumos I e Novos Rumos II, nas quais empresas privadas, universidades e centros de pesquisa foram autuados por acesso indevido ao PGN e ao CTA. O volume das multas aplicadas por estas operações sensibilizou os interessados acerca da importância da regularização das atividades.

Em sua primeira fase, a Operação Novos Rumos I fiscalizou 107 processos administrativos sobrestados desde 2007 referentes ao acesso ao PGN e ao CTA, os quais foram encaminhados pelo Departamento de Patrimônio Genético ao setor de fiscalização do IBAMA. A Operação Novos Rumos I resultou em 23 advertências, 135 autuações e multas que superaram os R\$ 100 milhões. Em 2011/2012, a Operação Novos Rumos II fiscalizou 35 empresas suspeitas de realizarem atividades de acesso irregulares, lavrando 220 autos de infração, totalizando R\$ 88 milhões em multas (Ferreira \& Sampaio, 2013). 
As análises dos registros apresentados nos relatórios anuais de atividades do CGEN também resultaram na identificação de quatro tipos de autorizações de acesso ao PGN e CTA: i) Autorização Simples de Acesso ao PGN; ii) Autorização Especial de Acesso ao PGN; iii) Autorização Simples de Acesso ao CTA; iv) Autorização Simples de Acesso ao PGN e ao CTA.

Verificou-se que o número de Solicitação de Autorização de Acesso relacionados à Autorização Simples de acesso ao PGN (57,99\%) prevaleceu durante o período analisado, seguido por Solicitação de Autorização Especial de acesso ao PGN $(18,53 \%)$, Solicitação de Autorização Simples de acesso ao CTA $(11,95 \%)$ e Solicitação de Autorização Simples de acesso mútuo ao PGN e ao CTA (11,50\%) (Figura 2).

Em decorrência, o número de concessões de Autorização Simples de acesso ao PGN $(54,12 \%)$ também prevaleceu, seguido por Autorização Especial de acesso ao PGN (19,82\%), Autorização Simples de acesso ao CTA (18,15\%) e Autorização Simples de acesso ao PGN e CTA (7,92\%) (Figura 3).

Figura 2. Série histórica dos registros oficiais brasileiros de Solicitações de Autorização de Acesso ao PGN e/ou CTA no período de 2002 a 2014 por tipo de Autorização.

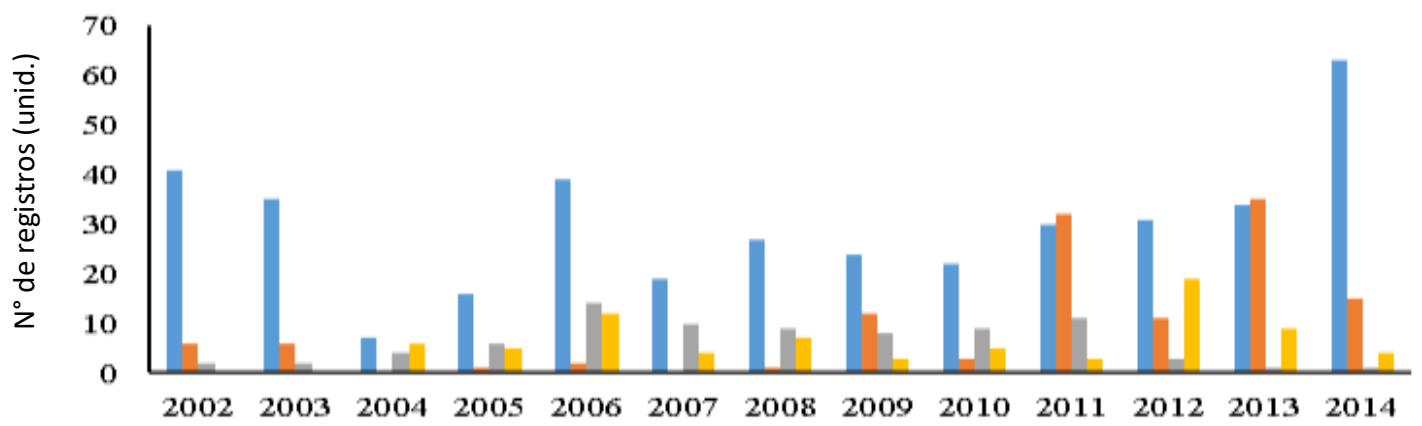

Ano

- Processos Autuados com Solicitação de Autorização Simpl es de Acesso ao PGN

Erocessos Autuados com Solicitação de Autorização Especial de Acesso ao PGN

= Processos Autuados com Solicitação de Autorização Simpl es de Acesso ao CTA

= Processos Autuados com Solicitação de Autorização Simpl es de Acesso ao PGN e CTA

Fonte: Autores, baseado em dados de Brasil/MMA (2015b). 
Figura 3. Série histórica dos registros oficiais brasileiros de Autorizações Concedidas pelo CGEN para Acesso ao PGN e/ou CTA no período de 2002 a 2014 por tipo de Autorização (unid.)

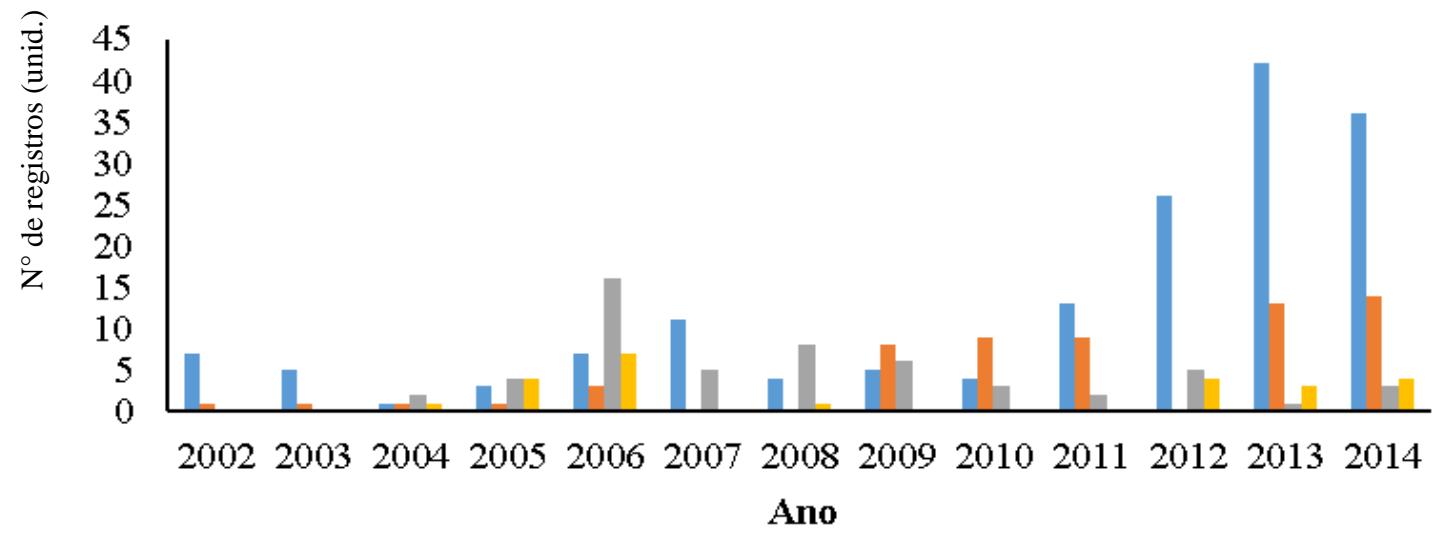

\author{
Autorizações Simples Concedidas para o Acesso ao PGN \\ Autorização Especial Concedida para o Acesso ao PGN \\ Autorização Simples Concedida para o Acesso ao CTA \\ - Autorização Simples Concedida para o Acesso ao PGN e CTA \\ Fonte: Autores, baseado em dados de Brasil/MMA (2015b).
}

Os crescimentos dos números de registros de Solicitação de Autorização de Acesso e de Autorização Concedidas atinentes ao PGN estão relacionados às execuções das operações de fiscalização; entretanto, também estão relacionados ao crescimento do mercado internacional de produtos farmacêuticos e cosméticos formulados com elementos da biodiversidade brasileira, conforme cenário apresentado por Miguel (2012), haja vista que estes setores industriais vêm apresentando há mais de dez anos crescimento em suas escalas comerciais, conforme panoramas apresentado pelas associações dos respectivos setores industriais (INTERFARMA, 2018; ABIHPEC, 2018).

\title{
5.2 Análise das deliberações de acesso ao CTA concedidas pelo CGEN durante vigência da MP 2.186 / 2001 (2002 -
} 2014)

As análises das deliberações de acesso ao CTA concedidas pelo CGEN durante vigência da MP 2.186/2001 resultaram na identificação de 66 deliberações de atividades de pesquisa científica, bioprospecção ou desenvolvimento tecnológico com acesso ao CTA entre os anos de 2004 e 2015. Verificou-se que o somatório das deliberações de acesso ao CTA publicadas no site do CGEN até o ano de 2015 foi equivalente a 83,54\% do total de autorizações concedidas divulgadas nos relatórios anuais de atividades do CGEN.

A análise da série histórica destas deliberações demonstra maiores concentrações entre os anos de 2005 e 2010 (Figura 4), com pequeno crescimento após promulgação do Decreto 5.459/2005, baseando-se nos resultados dos estudos de Carvalho et al. (2008a) que inferiam no ano de 2006 a existência de 512 medicamentos fitoterápicos registrados na ANVISA derivados de aproximadamente 162 extratos de plantas medicinais e outros derivados, dentre os quais $25 \%$ destes contavam com espécies vegetais nativas da América do Sul (Carvalho et al., 2008b).

Considera-se que uma lacuna jurídica presente durante a primeira metade do período de vigência da MP 2.186/2001 foi um dos fatores que contribuiu coma baixa perspectiva de regularização, pois comprometeu as aplicações de sanções ou penalidades àqueles em inconformidade frente à legislação vigente: a ausência do estabelecimento do processo administrativo federal para apuração destas infrações. Esta lacuna somente foi preenchida após a promulgação do Decreto 6.514/2008, o qual 
"dispõe sobre as infrações e sanções administrativas ao meio ambiente e estabeleceu o processo administrativo federal para apuração destas infrações", que foi promulgado após um período de dez anos desde o início da vigência da Lei de Crimes Ambientais no ano de 1998 (Lei 9.605/1998). Por estabelecer o processo administrativo necessário, o Decreto 6.514/2008 apresentou maiores efeitos em relação à punição do acesso indevido ao CTA quando comparado com o Decreto 5.459/2005, haja vista que também proporcionou as execuções das Operações Novos Rumos.

Figura 4. Série histórica de registros de Deliberações de acesso ao CTA autorizadas pelo CGEN entre os anos de 2004 e 2015 (unid.)

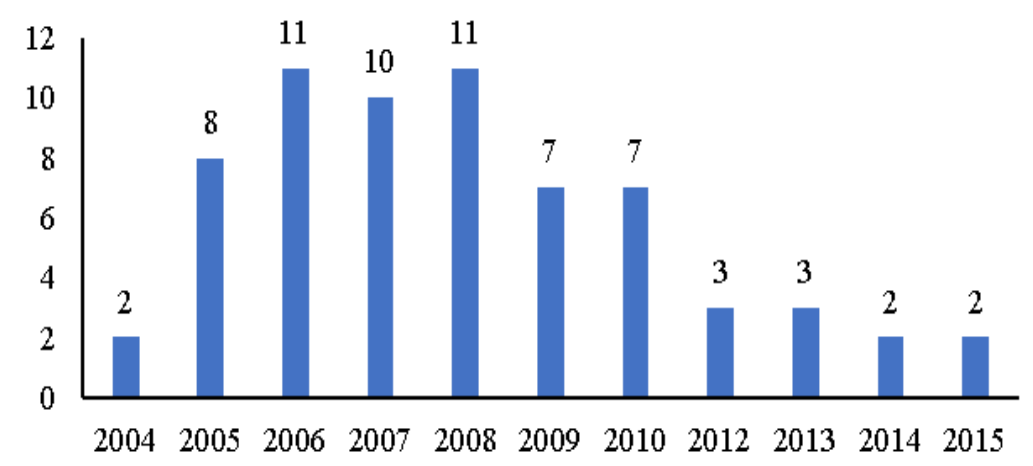

Fonte: Autores, baseado em dados de Brasil/MMA (2016b).

No que se refere aos tipos de interessados em acessar o CTA, verificou-se que os centros de pesquisa do Estado Brasileiro se destacaram quanto ao número de registros e representaram 53,03\% do total de deliberações de acesso ao CTA concedidas, seguidos pelas universidades brasileiras que somaram 36,36\%, as empresas privadas que atingiram 7,58\%, e as organizações não-governamentais que representaram apenas 3,03\% (Figura 5).

Figura 5. Percentuais dos tipos de interessados registrados nas Deliberações de Acesso ao CTA autorizadas pelo CGEN entre os anos de 2004 e 2015.

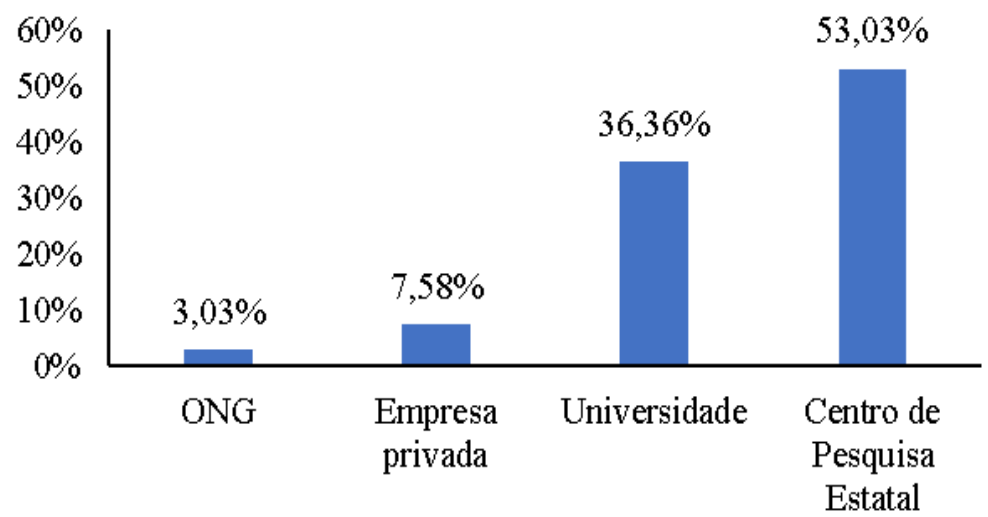

Fonte: Autores, baseado em dados de Brasil / MMA (2016b).

A Empresa Brasileira de Pesquisa Agropecuária (Embrapa) (18,18\%), o Museu Paraense Emílio Goeldi (16,66\%), o Instituto Nacional de Pesquisas da Amazônia (INPA) (10,60\%) e o Instituto de Pesquisas Jardim Botânico do Rio de Janeiro $(6,06 \%)$ foram os centros de pesquisa do Estado Brasileiro que se destacaram quanto ao número de deliberações de acesso ao CTA obtidas.

Os dados analisados também demonstram que a soma dos registros apresentados por Universidades brasileiras da Região Sudeste foi responsável por 19,69\% do total de registros, enquanto as Universidades da Região Centro-Oeste 
corresponderam a 12,12\% do total de registros, as quais se destacaram em relação às demais regiões do Brasil. Com relação às empresas privadas, identificaram-se registros apenas em nome da empresa Natura Inovação e Tecnologia de Produtos LTDA, a qual obteve 5 deliberações de acesso.

No que se refere aos tipos de autorização de acesso ao CTA, a análise demonstrou que a pesquisa científica com acesso ao CTA foi responsável por $92,42 \%$ do total de deliberações identificadas, conforme Figura 6 . Acerca das atividades com previsão de exploração econômica, foram identificadas 4 deliberações de atividades de bioprospecção e desenvolvimento tecnológico $(6,06 \%)$ e 1 deliberações de atividade de desenvolvimento tecnológico $(1,52 \%)$, todas concedidas para a empresa Natura Inovação e Tecnologia de Produtos LTDA (Figura 6).

Figura 6. Percentuais de tipos de autorizações de acesso aos CTA deliberadas pelo CGEN entre os anos de 2004 e 2015

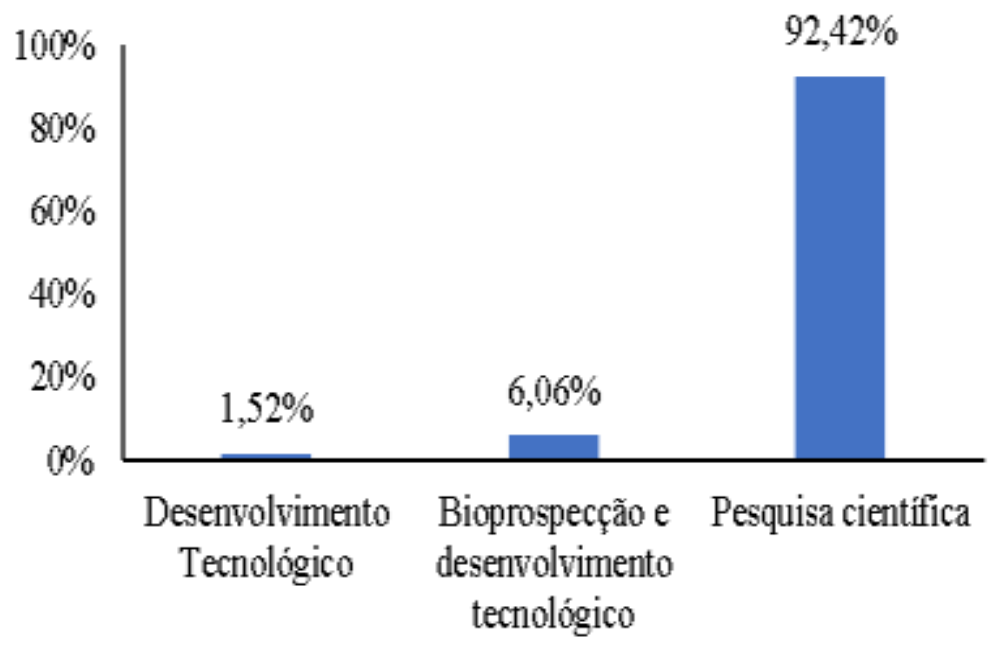

Fonte: Autores, baseado em dados de Brasil / MMA (2016b).

Neste sentido, verifica-se que os centros de pesquisa e universidades brasileiras foram os principais responsáveis pelo desenvolvimento de pesquisa científica com acesso ao CTA durante a vigência da MP 2.186/2001, enquanto que as solicitações de acesso legal com vistas às explorações econômicas e comerciais de produtos ou processos baseados em CTA, no Brasil, foram conduzidos unicamente por empresas privadas durante este período.

Desse modo, pode-se considerar que a Lei de Inovação Tecnológica de 2004 (Lei № 10.973, de 02 de dezembro de 2004), a qual criou mecanismos de incentivo aos pesquisadores públicos interessados em comercializar suas invenções ou inovações tecnológicas, não proporcionou relevantes impactos no sentido de incentivar a comercialização de produtos tecnológicos baseados no acesso legal ao CTA desenvolvidos por pesquisadores de universidade e centros de pesquisa nacionais.

Com relação aos Estados da Federação nos quais foram realizados acessos ao CTA, verifica-se considerável participação dos Estados da Região Norte, com destaques ao Estado do Amazonas (19,70\%) e ao Estado do Pará (15,15\%). Verificou-se que a Região Norte correspondeu a 51,52\% do total de deliberações de acesso ao CTA registradas entre 2004 e 2015, a qual foi seguida pela Região Centro-Oeste, que apresentou 24,26\% do total de registros.

O maior número de registros acesso legal aos CTA na Região Norte pode estar relacionado a dois fatores: i) constitui a região de origem e elevada concentração de diversas espécies da biodiversidade nacional utilizadas como matérias primas no desenvolvimento de novos produtos tecnológicos; ii) apresenta elevada concentração de povos indígenas e comunidades tradicionais provedores e detentores de CTA. Ambos fatores aumentam as probabilidades de identificação de potenciais PGN e CTA nesta região. 
Diversas espécies da biodiversidade nacional, nativas do bioma Amazônia, como açaí, andiroba, breu, castanha do Pará, copaíba, cupuaçu, murumuru, pau-rosa, priprioca, tucumã, etc., aplicadas na fabricação de inúmeros cosméticos, produtos de higiene pessoal ou perfumaria presentes no mercado internacional (Isaac, 2016; Miguel, 2012), advêm dos Estados da Região Norte, que também se destacam em volumes de produção (IBGE, 2020; Homma, 2014). Simultaneamente, os Estados da Região Norte apresentam as maiores concentrações populacionais de indígenas do país, tanto em zona rural quanto em zona urbana. O Censo do ano de 2010 registrou o total de 818 mil indígenas no Brasil, dos quais 306 mil estão na Região Norte (IBGE, 2018). Além disso, esta região também apresenta um elevado número de comunidades tradicionais, muitas das quais estão organizadas em entidades representativas e movimentos sociais (Almeida \& Farias Júnior, 2013).

No que se refere às áreas de acesso aos CTA, foram identificadas 5 diferentes categorias de unidade de conservação do meio ambiente, baseadas no Sistema Nacional de Unidades de Conservação (SNUC), quais sejam: Área de Proteção Ambiental (APA), Parque (Nacional e Estadual), Reserva de Desenvolvimento Sustentável (RDS), Floresta Nacional (FLONA) e Reserva Extrativista (RESEX), além de Território Indígena (TI). Contudo, verificou-se que quase metade das deliberações $(45,45 \%)$ mantiveram sigilo de informações referentes às áreas de acesso aos CTA, as quais podem também ter sido realizadas em propriedades privadas ou em terras devolutas. Ao tempo, confere-se destaque aos Territórios Indígenas $(36,36 \%)$ enquanto principais áreas de acesso ao CTA.

Acerca dos povos tradicionais provedores ou detentores de CTA identificados nesta pesquisa, verificou-se participação dos povos indígenas em 37,88\% das atividades de acesso ao CTA anuídas até o ano de 2015. Dentre os povos indígenas identificados, verificou-se participação dos povos: Baniwa, Wajãpi, Xingu, Kayabi, Mebengokre-Kayaapó, Kayapó e Pankararu. Os dados identificados também possibilitaram verificar que os centros de pesquisa estatais foram responsáveis por 72,0\% das Deliberações de Acesso ao CTA de povos indígenas, correspondendo a 18 registros, enquanto que as universidades apresentaram 5, ONG apenas 2, e empresas privadas não apresentaram nenhum. Os centros de pesquisa estatais que desenvolveram atividades com CTA indígena foram o Museu Paraense Emilio Goeldi, com 7 deliberações, a EMBRAPA, com 6 deliberações, e a INPA, com 5 deliberações.

A maior proporção de acessos aos CTA realizados pelos centros de pesquisa mencionados pode estar relacionada à localização das entidades identificadas. O Museu Paraense Emílio Goeldi está instalado na cidade de Belém, Estado do Pará; o Instituo Nacional de Pesquisas da Amazônia (INPA), está instalado na cidade de Manaus, Estado do Amazonas; e a EMBRAPA possui estruturas instaladas tanto no Estado do Pará quanto no Estado do Amazonas. Considera-se que a proximidade geográfica facilita as ações de acesso aos provedores de CTA, o que contribui com a regularização dos trâmites legais relacionados.

Dentre as comunidades tradicionais cujos acessos aos CTA foram autorizados, verificam-se os quilombolas $(7,58 \%)$, extrativistas $(4,55 \%)$, caiçaras $(4,55 \%)$, agricultores tradicionais $(4,55 \%)$, ribeirinhos $(3,03 \%)$, pescadores artesanais $(3,03 \%)$, geraizeiros $(3,03 \%)$, raizeiros $(1,52 \%)$ e erveiras e erveiros urbanos (1,52\%). Apenas $15,15 \%$ das deliberações não divulgaram quais povos e comunidades tradicionais estariam envolvidos com as ações.

Udry et al. (2015) apresentaram a coletânea de atividades de pesquisa que o Estado Brasileiro vem desenvolvendo através da EMBRAPA que contaram com participações de povos e comunidades tradicionais do Brasil. Relata-se que entre as 47 Unidades da EMBRAPA, o total de 18 Unidades desenvolveram atividades junto aos povos e comunidades tradicionais totalizando 28 atividades/projetos de pesquisa. Em uma perspectiva regional, foram identificados 9 projetos na região CentroOeste, 7 no Norte, 4 no Nordeste e 7 na região Sul. Nas categorias de grupos sociais, constam 15 projetos com comunidades tradicionais geraizeiros, extrativistas, ribeirinhos, faxinalenses, quebradeiras de coco, etc.; 6 projetos com povos indígenas; 5 projetos com quilombolas; e 3 projetos com agricultores tradicionais.

Dentre as principais dificuldades para os desenvolvimentos das pesquisas realizadas pela EMBRAPA, relata-se: 
morosidade nos processos de obtenção de autorização do CGEN; dificuldades logísticas de acesso físico à comunidade; dificuldades em diálogos e aproximações junto às comunidades; falta de recursos financeiros e humanos; e morosidade de ações e excessiva burocracia em processos inerentes à pesquisa social (Udry et al., 2015).

\subsection{Análise dos cadastros de atividades com acesso ao CTA via SisGen durante vigência da Lei 13.123/2015 (2015 -}

Atual)

As análises dos registros de cadastros de projetos de pesquisa científica e desenvolvimento tecnológico com acesso a PGN e/ou CTA divulgados pelo SisGen durante período de vigência da Lei 13.123/2015 até o mês de dezembro do ano de 2020 resultou na identificação de um total de 57.910 (cinquenta e sete mil, novecentos e dez) cadastros, que correspondem às autorizações automáticas de acesso legal (Brasil/MMA, 2020).

Verificou-se que, diferentemente dos dados divulgados durante período de vigência da MP 2.186/2001, o SisGen não divulga dados relacionados à série histórica, tipo de atividade cadastrada (pesquisa científica ou desenvolvimento tecnológico), povos e comunidades tradicionais envolvidos com as atividades e as espécies da biodiversidade relacionadas, salvo os casos que são citadas nos títulos dos cadastros. Destes indicadores, apenas as informações relacionadas à série histórica de cadastros via SisGen foram identificados no sítio eletrônico do CGEN.

Avalia-se que a indisponibilização destas informações prejudica tanto as análises das efetividades das políticas públicas relacionadas à preservação e uso sustentável do PGN e do CTA quanto as análises dos níveis de desenvolvimento tecnológico dos produtos e dos processos associados. Ademais, estas informações podem contribuir com criações de bancos de dados de CTA, os quais podem auxiliar ações de identificação e seleção de indicadores que subsidiam tomadas de decisões por grupos sociais envolvidos com o tema.

Os resultados das análises comparativas das séries históricas de Autorizações de Acesso ao PGN e CTA registradas durante a MP 2.186/2001 em face aos cadastros divulgados pelo SisGen durante vigência da Lei 13.123/2015 apresentam acentuado crescimento do número de registros anuais após a implementação deste sistema (Figura 7). Os registros realizados a partir do ano de 2015 se referem tanto ao cadastro de regularizações de atividades quanto aos cadastros de novas atividades. A elevação do número de registros verificada no ano de 2018 ocorreu em virtude do encerramento do prazo de regularização de projetos de pesquisa científica junto ao CGEN via SisGen que era previsto para esse ano.

Verifica-se o efeito positivo no sentido quantitativo em relação ao crescimento do número de atividades regularizadas após a implementação da nova legislação nacional e do sistema SisGen, inclusive contribuindo com regularizações de atividades desenvolvidas durante a vigência da MP 2.186/2001. 
Research, Society and Development, v. 10, n. 4, e26510413999, 2021

(CC BY 4.0) | ISSN 2525-3409 | DOI: http://dx.doi.org/10.33448/rsd-v10i4.13999

Figura 7. Série histórica dos registros oficiais brasileiros de solicitações de autorização de acesso e de autorizações concedidas relacionadas ao acesso ao PGN e/ou CTA no período de 2002 a 2014 e série histórica dos cadastros de atividades com acesso ao PGN e/ou CTA cadastradas no SisGen entre os anos de 2017 e 2020 (unid.; escala logarítmica).

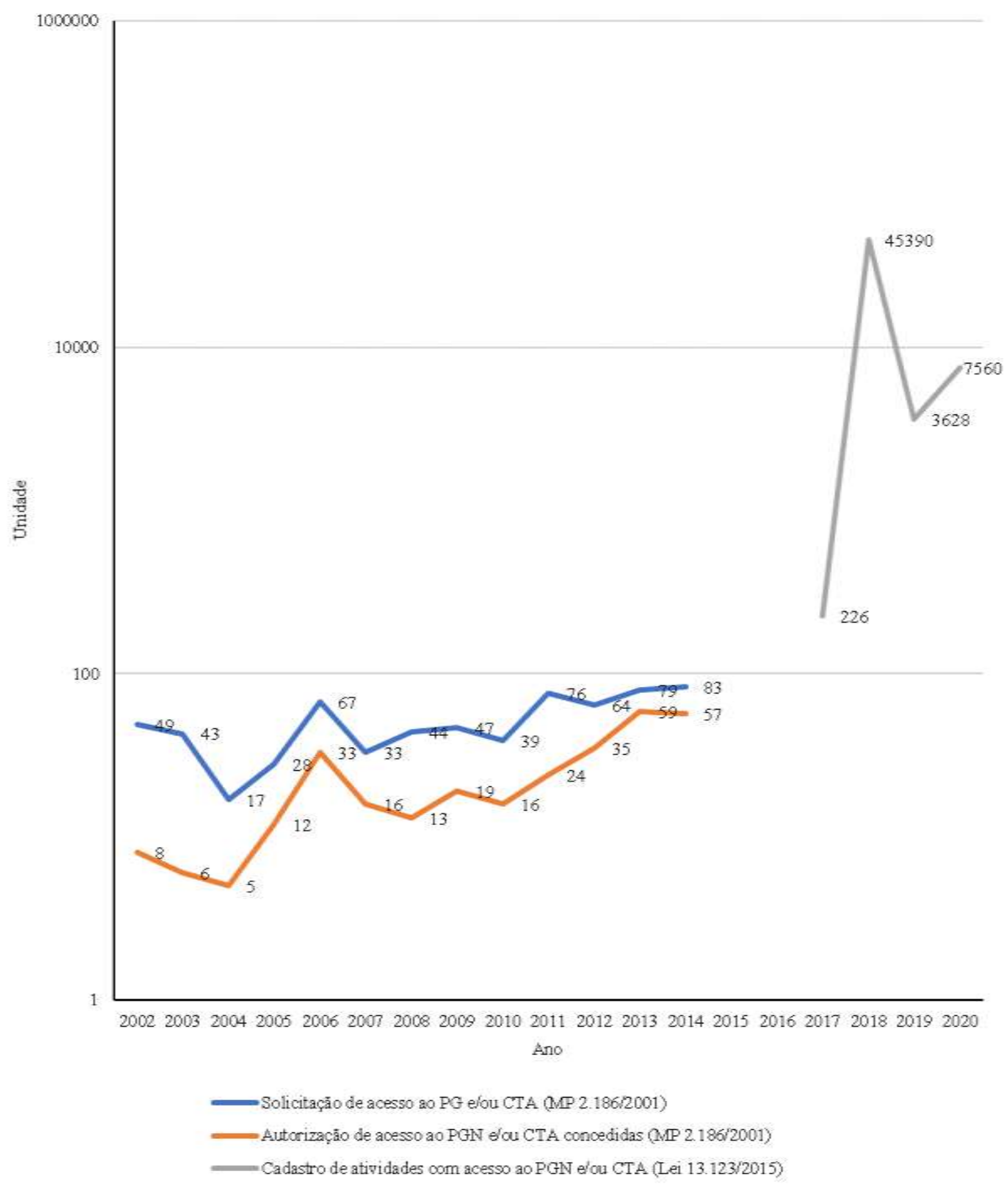

Fonte: Autores, baseado em dados de Brasil / MMA (2016b) e Brasil / MMA (2020).

Com relação aos objetos de acesso registrados nas atividades cadastradas no SisGen, verificou-se majoritária parcela dos registros relacionados ao PGN $(82,12 \%)$ quando comparado aos números de registros relacionados às aplicações de PGN e CTA $(12,99 \%)$ e CTA $(4,90 \%)$ (Figura 8$)$, apresentado maior proporção de cadastros vinculados ao acesso ao PGN quando comparado com o período de vigência da MP 2.186/2001. 
Figura 8. Percentuais dos objetos de acesso registrados nos cadastros de atividades via SisGen entre os anos de 2017 e 2020.

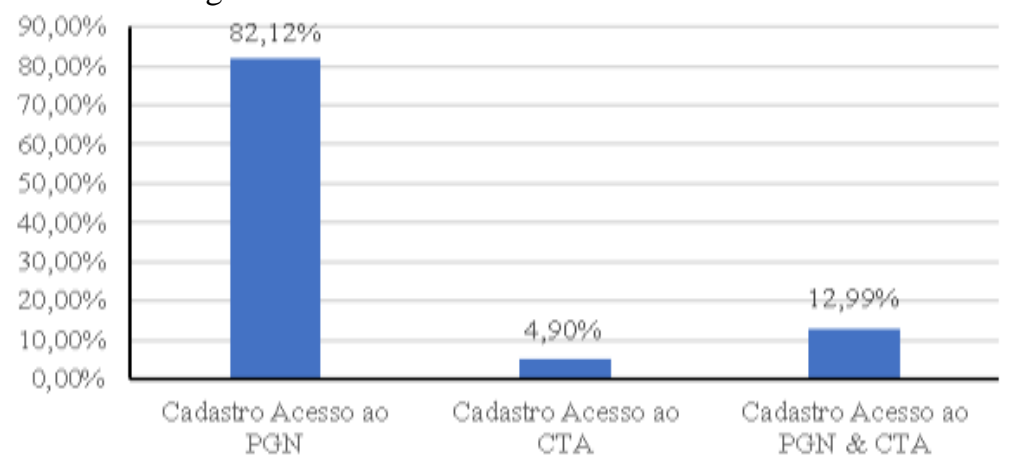

Fonte: Autores, baseado em dados de Brasil / MMA (2020).

Os dados divulgados pelo SisGen possibilitaram verificar os percentuais dos tipos de interessados no acesso legal ao PGN e/ou CTA. Neste sentido, verificou-se elevado percentual de universidades (54,32\%), pessoas físicas (30,31\%) e cento de pesquisa estatal $(9,6 \%)$ nos três tipos de modalidades de objeto de acesso (Figura 9). O percentual de registros atribuídos às universidades brasileiras pode ser ainda superior, haja vista que muitos dos pesquisadores registrados nos cadastros são pesquisadores vinculados às universidades brasileiras, pelas quais as pesquisas são desenvolvidas.

Figura 9. Percentuais dos tipos de interessados registrados nos cadastros de atividades com acesso ao PGN e/ou CTA via SisGen, entre os anos de 2017 e 2020.

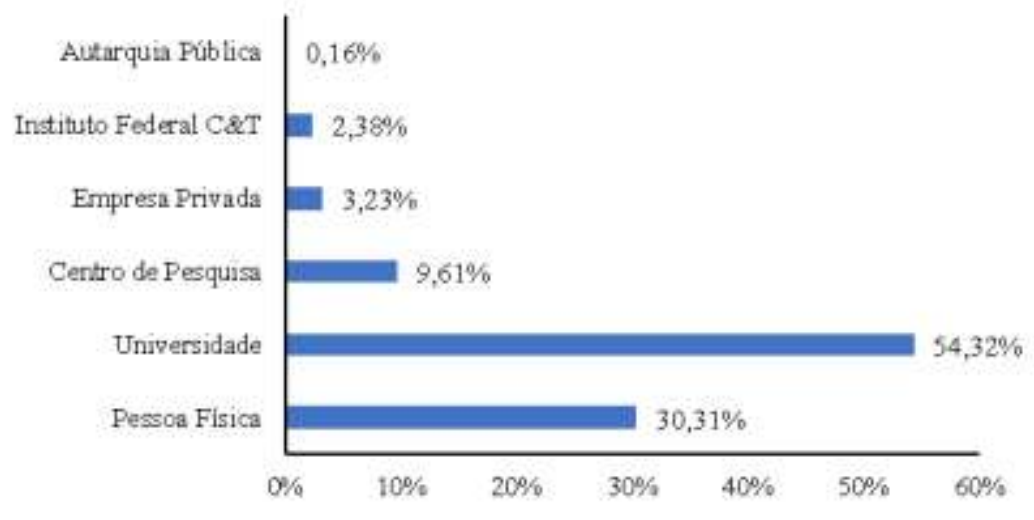

Fonte: Autores, baseado em dados de Brasil / MMA (2020).

Além das universidades brasileiras e pesquisadores brasileiros, verificou-se crescimento da regularização de atividades desenvolvidas por institutos federais de educação, ciência e tecnologia e autarquias públicas (Figura 9), os quais não foram identificados nos registros do período de vigência da MP 2.186/2001.

Os dados divulgados pelo SisGen (Brasil/MMA, 2020) possibilitaram analisar os percentuais de participação dos objetos de acesso das atividades cadastradas por tipo de interessado. Neste sentido, verificou-se que em relação ao acesso ao CTA, ao acesso mútuo ao PGN \& CTA e ao acesso ao PGN, as universidades se destacaram em relação às suas participações, que corresponderam à 48,59\%, 48,91\% e 55,52\%, respectivamente, seguidos pelos registros de pessoas físicas, que apresentaram 40,60\%, 40,64\% e 28,06\%, respectivamente (Figuras 10, 11 e 12). 
Figura 10. Percentuais dos tipos de interessados registrados nos cadastros de atividades com acesso ao CTA via SisGen, entre os anos de 2017 e 2020.

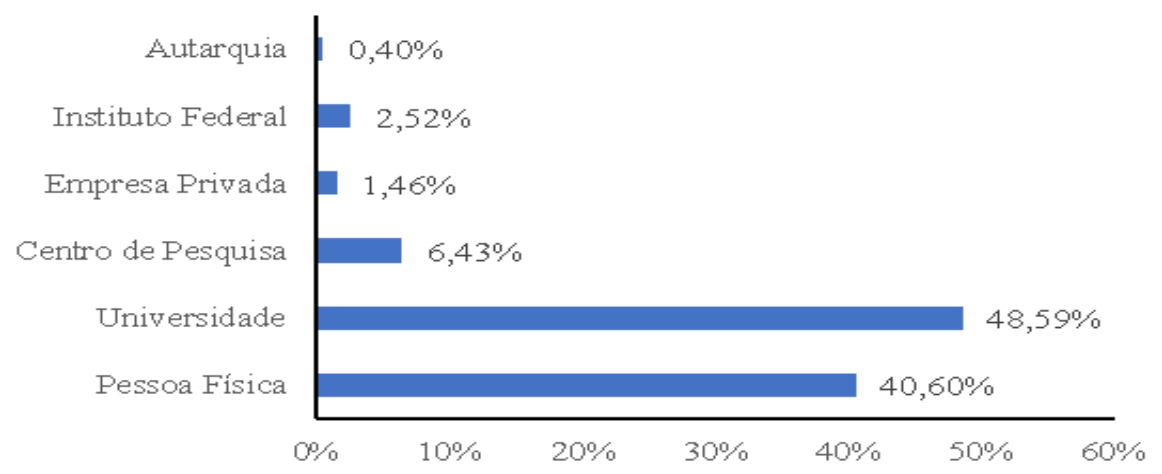

Fonte: Autores, baseado em dados de Brasil / MMA (2020).

Figura 11. Percentuais dos tipos de interessados registrados nos cadastros de atividades com acesso ao PGN e CTA via SisGen, entre os anos de 2017 e 2020.

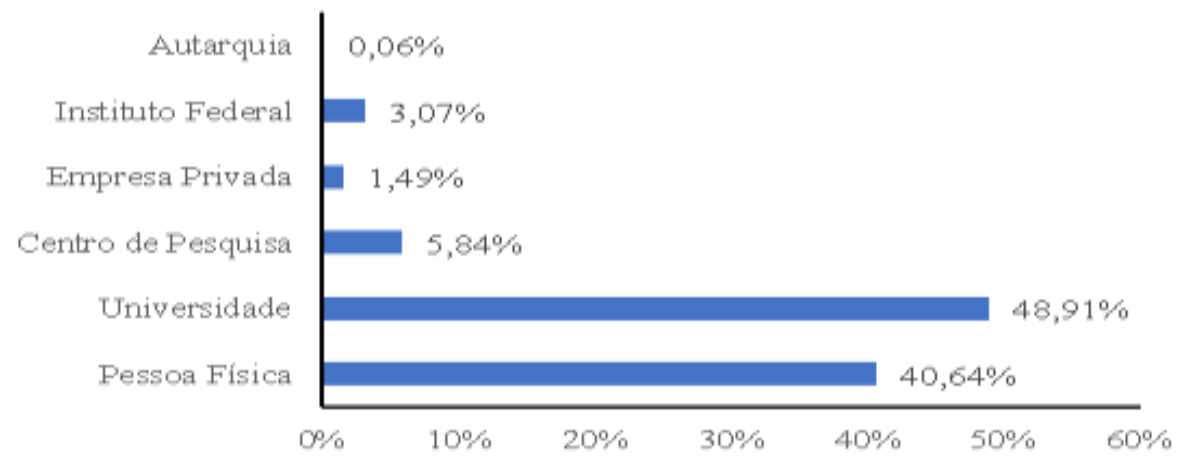

Fonte: Autores, baseado em dados de Brasil / MMA (2020).

Figura 12. Percentuais dos tipos de interessados registrados nos cadastros de atividades com acesso ao PGN via SisGen, entre os anos de 2017 e 2020.

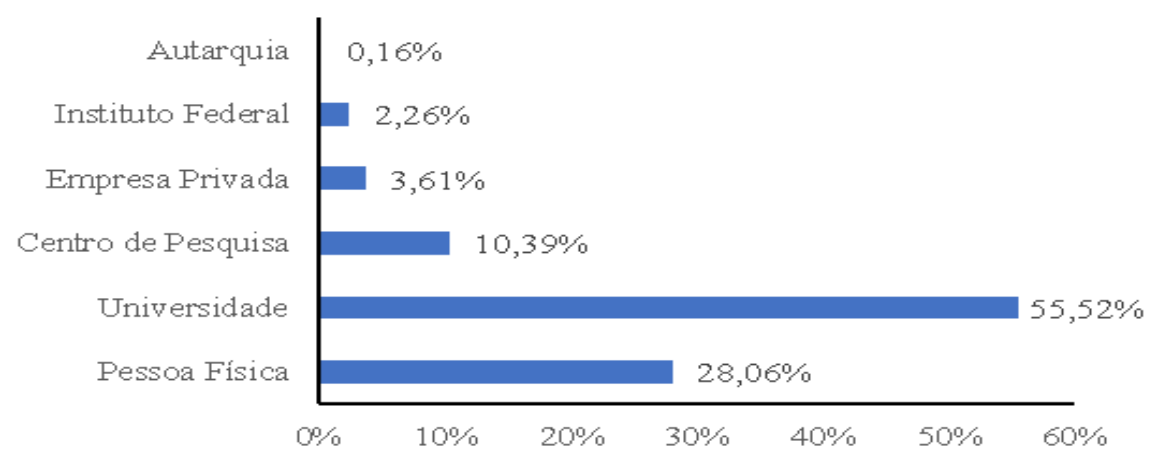

Fonte: Autores, baseado em dados de Brasil / MMA (2020).

Os resultados desta pesquisa demonstram o elevado crescimento do número de registros de atividades com acesso legal ao CTA no Brasil que foi proporcionado pelas alterações apresentadas pela Lei 13.123/2015, sobretudo, em relação à regularização automática via SisGen. Como resultado, proporcionou-se a regularização de novas atividades com acesso ao PGN e/ou CTA em paralelo à regularização de atividades deste tipo desenvolvidas durante a vigência da MP 2.186/2001.

De acordo com Dutra et al. (2016), o levantamento de pesquisas científicas relacionadas às espécies medicinais da biodiversidade publicadas por pesquisadores brasileiros, apresentam que, entre os anos de 2009 e 2011 foram publicados 4.781 
artigos científicos, entre os anos de 2011 e 2013 foram publicados 10.474 mil artigos científicos, e entre os anos de 2013 e 2015 foram publicados 9.875, corroborando, portanto, com o resultado desta pesquisa, em razão do elevado número de pesquisas científicas relacionadas que se evidencia.

Apesar do SisGen possibilitar a facilitação das regularizações das atividades científicas e comerciais com acesso ao CTA, este sistema não apresenta ferramentas que possibilitem um eficaz monitoramento de atividades indevidas mediante interesse e análises desenvolvidas por parte da sociedade civil, e atrelado à reduzida infraestrutura destinadas ao controle da prática da biopirataria no Brasil, avalia-se que o SisGen não apresenta em sua interface pública garantias de que ações indevidas ou lesivas possam ser monitoradas pela sociedade civil.

De acordo com o Tribunal de Contas da União do Brasil (TCU) (2016), a pouca atuação empregada pelo Estado Brasileiro nas ações de combate à biopirataria pode facilitar a ação de corporações que têm interesses comerciais no PGN e CTA, trazendo grandes prejuízos às populações tradicionais e à Nação, que deveriam ter parcelas desses ganhos repartidos. Assim, o órgão cita a falta de percepção do Governo Federal acerca da questão biopirataria constitui um problema que afeta os interesses nacionais, haja vista que a biopirataria é prática nociva aos interesses nacionais, e assim deve ser combatida para evitar prejuízos econômicos, sociais e danos ao meio ambiente.

A comercialização desses recursos naturais como matéria-prima na forma de rasurados, secos e embalados possui um minúsculo valor quando comparado ao produto final. Para algumas espécies, o valor médio de comercialização da matériaprima na forma bruta chega a ser $800 \%$ abaixo do produto final no mercado. Na maioria dos casos, esse produto final representa apenas a adição de pequenos processos de baixo custo, tais como embalagem individual, produção de tinturas, rotulagem e outros, muitos dos quais poderiam ser facilmente realizados localmente, o que conferiria um valor agregado gigantesco ao produto florestal explorado em seu local de origem (Di Stasi et al., 2004).

Em paralelo, dados apresentados pela Organização de Complexidade Econômica (OCE) (2018) demonstram que o Brasil, no ano de 2017, apresentou um relevante déficit em suas relações comerciais internacionais de produtos químicos gerais, apresentando um valor de exportação de US\$ 9,12 bilhões, enquanto que sua importação correspondeu a US\$ 28,7 bilhões.

Uma possível contribuição para este déficit pode ser o fato de que os produtos químicos possivelmente advindos da biodiversidade brasileira identificados nas exportações do Brasil são aplicados em outros países na fabricação de produtos finais de alto valor agregado e que, posteriormente, são importados pelo Brasil. Os produtos que se referem são: óleos essenciais, ceras, breu e terebintina - que podem ser aplicados na linha de produção de cosméticos, perfumes e etc.; compostos fenólicos, alcaloides vegetais e pigmentos - que podem ser aplicados nas linhas de produção de medicamentos embalados ou não embalados; e corantes animais/vegetais - que podem ser aplicados nas linhas de produção de alimentos, produtos químicos ou cosméticos.

Dentro desta realidade, o próprio CTA de povos e comunidades tradicionais do Brasil vem sendo explorado tecnologicamente por empresas privadas no exterior, conforme prospecções tecnológicas desenvolvidas baseando em informações apresentadas pelos bancos de dados patentários (Souza, 2019).

Neste contexto, o TCU considera que ações de combate a biopirataria devem ser pautadas por levantamento de informações de inteligência para se ter a efetividade esperada, pois a simples fiscalização de bagagens e cargas em portos e aeroportos é insuficiente para se garantir de forma mínima a soberania nacional sobre os valiosos PGN e CTA. Para tanto, avalia-se necessário a estruturação de equipes regionais, com coordenação nacional, para alcançar tais objetivos de forma efetiva (TCU, 2016).

Neste sentido, considera-se que a criação de banco de dados de CTA nacionais poderia contribuir com registros e divulgações das aplicações do CTA e suas origens, o que contribuiria com melhorias no monitoramento e controle por parte 
dos órgãos competentes responsáveis por fiscalizar o acesso legal e por conceder autorizações ou diretos de propriedade intelectual, os quais serão mais exigidos nos próximos anos diante do cenário de expectativa de crescimento da comercialização de produtos tecnológicos formulados com estes elementos.

\section{Considerações Finais}

Em decorrência das alterações nas regras do acesso legal ao PGN e ao CTA que foram proporcionadas pela promulgação da Lei 13.123/2015, verificou-se relevante crescimento do número de registros de atividades científicas e tecnológicas com acesso tanto ao PGN quanto ao CTA regularizadas no Brasil, o que foi impulsionado pela implementação do SisGen, um sistema responsável pelo cadastro destas atividades que resulta na deliberação automática, salvo para reduzido número de exceções.

Ao final do ano de 2020, após o quinto ano de vigência da Lei 13.123/2015, foram identificadas mais de 58 mil autorizações de atividades com acesso ao PGN e/ou ao CTA regularizadas, enquanto que durante os 15 anos de vigência da MP 2.186/2001 foram regularizadas apenas 303 atividades.

Apesar da amplitude na diferença dos números de registros de autorizações quando comparados os dois períodos analisados, os percentuais de acesso aos diferentes tipos de objetos de acesso (PGN, CTA ou PGN \& CTA) não apresentaram grandes disparidades entre estes dois períodos, contudo, em ambos períodos o número de registros de acesso ao PGN prevaleceu. Em paralelo, verificou-se maior participação das universidades e centros de pesquisa nas ações de regularização do acesso ao CTA, as quais estiveram relacionadas em maior proporção às atividades de pesquisa científica.

Com relação ao tipo de atividade, apesar do SisGen não disponibilizar informações necessárias à análise das distribuições percentuais das atividades de pesquisa científica e desenvolvimento tecnológico, considera-se que o maior percentual atribuído às atividades de pesquisa científica observado durante a vigência da MP 2.186/2001 foi mantido durante o período de vigência da Lei 13.123/2015 analisado em função da manutenção da distribuição percentual dos objetos de acesso e dos atores sociais vinculados, com grandes participações das universidade e seus pesquisadores vinculados.

Corrobora com esta afirmação o resultado da análise de dados divulgados pelo SisGen que demonstram que as universidades representaram até o ano de 2020 o equivalente a $0,25 \%$ do total de notificações de produtos finais destinados ao comércio, enquanto que os centros de pesquisa representaram apenas $0,18 \%$. Por sua vez, as empresas privadas representaram aproximadamente $90 \%$ do total de notificações deste tipo. Os fatores associados a essas baixas perspectivas comerciais por parte das universidades e centros de pesquisa podem ser analisados por pesquisas futuras a fim de elucidar as causas e efeitos.

Os resultados deste estudo permitem considerar que o novo arcabouço jurídico nacional relacionado ao acesso legal ao PGN e ao CTA conexo às novas ferramentas da tecnologia da informação, ambas focadas na presteza da concessão automática de deliberações, consolidaram a perspectiva de celeridade do processo de regularização de atividades com acesso ao PGN ou CTA, que supostamente poderá contribuir com benefícios econômicos mediante os sinais de alavancagem do mercado mundial de produtos da biodiversidade. Assim, os benefícios econômicos auferidos e repartidos por este mercado também deverão ser analisados por pesquisas futuras.

Concomitante, avalia-se que a transparência de informações se encontra prejudicada em virtude da indisponibilização de informações que eram divulgadas pelo CGEN durante vigência da MP 2.186/2001. Estas informações podem ser úteis à criação de banco de dados de CTA, os quais podem auxiliar ações de identificação e seleção de indicadores que subsidiam tomadas de decisões por grupos sociais envolvidos com o tema, sobretudo em relação às ações focadas no atendimento às diretrizes apresentadas pela Convenção sobre Diversidade Biológica de 1992, Protocolo de Nagoya de 2011 e Lei 13.123/2015. 


\section{Agradecimentos}

Agradecemos à Coordenação de Aperfeiçoamento de Pessoa de Nível Superior do Brasil (CAPES) pela concessão de bolsa de pesquisa científica.

\section{Referências}

ABIHPEC. (2018). Panorama do setor 2018: Resultados de 2017. São Paulo. ABIHPEC - Associação Brasileira da Industria de Higiene Pessoal, Perfumaria e Cosméticos.

Almeida, A. W. B., \& Farias Júnior, E. de A. (Orgs.). (2013). Povos e comunidades tradicionais: Nova cartografia social. UFAM.

Alier, J. M. (2012). El ecologismo de los pobre: conflitos ambientales y linguajes de valoración. Contexto.

Barbosa, B. (2017). Incongruência nas estratégias ou estratégia da incongruência: um estudo da relação entre TRIPs e CDB no espaço geográfico bra sileiro. Dissertação de mestrado, Universidade Federal de Santa Catarina, Programa de Pós-graduação em Geografia, Florianópolis, SC, Brasil.

Bertogna, V. A. \& Cibim, J. C. (2006). Acessos aos recursos genéticos e conhecimentos tradicionais associados: proteção de direitos e repartição de benefícios. In: Naster, S. H.; Rei, F. (org.). Direito Internacional do Meio Ambiente. Atlas.

Brasil. (2001). Medida Provisória n ${ }^{\circ} 2.186-16$, de 23 de agosto de 2001 . Regulamenta o inciso II do $\S 1^{\circ}$ e o $\S 4^{\circ}$ do art. 225 da Constituição, os arts. $1^{\circ}, 8^{\circ}$, alínea "j", 10, alínea "c", 15 e 16, alíneas 3 e 4 da Convenção sobre Diversidade Biológica, dispõe sobre o acesso ao patrimônio genético, a proteção e o acesso ao conhecimento tradicional associado, a repartição de benefícios e o acesso à tecnologia e transferência de tecnologia para sua conservação e utilização, e dá outras providências. Brasília: Diário Oficial da União, Brasília, de 24 ago. 2001. http://www.planalto.gov.br/ccivil_03/MPV/2186-16.htm.

Brasil. (2015a). Lei n ${ }^{\circ} 13.123$, de 20 de maio de 2015. Regulamenta o inciso II do $\S 1^{\circ}$ e o $\S 4^{\circ}$ do art. 225 da Constituição Federal, o Artigo 1 , a alínea j do Artigo 8, a alínea c do Artigo 10, o Artigo 15 e os $\$ \S 3^{\circ}$ e $4^{\circ}$ do Artigo 16 da Convenção sobre Diversidade Biológica, promulgada pelo Decreto no 2.519 , de 16 de março de 1998; dispõe sobre o acesso ao patrimônio genético, sobre a proteção e o acesso ao conhecimento tradicional associado e sobre a repartição de benefícios para conservação e uso sustentável da biodiversidade; revoga a Medida Provisória no 2.186-16, de 23 de agosto de 2001; e dá outras providências. Brasília: Diário Oficial da União, de 21 mai. 2015. http://www.planalto.gov.br/CCIVIL_03/_Ato2015-2018/2015/Lei/L13123.htm.

Brasil. (2016a). Decreto ${ }^{\circ}$ 8.772, de 11 de maio de 2016. Regulamenta a Lei $\mathrm{n}^{\mathrm{o}} 13.123$, de 20 de maio de 2015 , que dispõe sobre o acesso ao patrimônio genético, sobre a proteção e o acesso ao conhecimento tradicional associado e sobre a repartição de benefícios para conservação e uso sustentável da biodiversidade. Brasília: Diário Oficial da União, de 12 mai. 2016. http://www.planalto.gov.br/ccivil_03/_ato2015-2018/2016/decreto/D8772.htm.

Brasil. Ministério do Meio Ambiente. (2015b). Atividades do CGen durante a vigência da MP $\mathrm{n}^{\circ}$ 2.186-16/2001. Relatórios de Atividades. http://www.mma.gov.br/patrimonio-genetico/conselho-de-gestao-do-patrimonio-genetico/atividades-do-cgen-durante-a-vigencia-da-mp-n-2-186-162001/relatorio-de-atividades.html.

Brasil. Ministério do Meio Ambiente. (2016b). Atividades do CGen durante a vigência da MP n 2.186-16/2001. Deliberações de Autorizações de Acesso. http://www.mma.gov.br/patrimonio-genetico/conselho-de-gestao-do-patrimonio-genetico/atividades-do-cgen-durante-a-vigencia-da-mp-n-2-186-162001/atos-e-normas-do-cgen/delibera\%C3\%A7\%C3\%B5es-de-autoriza\%C3\%A7\%C3\%B5es-de-acesso.html.

Brasil. Ministério do Meio Ambiente. (2020). Sistema nacional de gestão do patrimônio genético nacional e do conhecimento tradicional associado Publicidade de cadastros e notificações. https://sisgen.gov.br/paginas/publicidade.aspx.

Brasil. (2005). Decreto ${ }^{\circ}$ 5.459, de 7 de junho de 2005. Regulamenta o art. 30 da Medida Provisória no 2.186-16, de 23 de agosto de 2001, disciplinando as sanções aplicáveis às condutas e atividades lesivas ao patrimônio genético ou ao conhecimento tradicional associado e dá outras providências. Brasília: Diário Oficial da União, de 8 jun. 2005. http://www.planalto.gov.br/ccivil_03/_Ato2004-2006/2005/Decreto/D5459.htm.

Carvalho, A. C. B., Balbino, E. E., Maciel, A. \& Perfeito, J. P. S. (2008a). Situação do registro de medicamentos fitoterápicos no Brasil. Revista Brasileira de Farmacognosia, (18:2), 314-319.

Carvalho, A. C. B., Santos, L. A. \& Silveira, D. (2008b). La regulación de los medicamentos herbarios en Brasil. Boletin Latinoamericano y del Caribe de Plantas Medicinales y Aromaticas, (8:1), 7-11.

Di Stasi, L. C., Stipp, E. J., Fascinelh, M. L., Gonzalez, F. G., Portela, T. Y., Mariot, A. \& Reias, M. S. (2004). Agregação de valor a produtos florestais manejados: 1. Espinheira Santa e suas adulterações; 2. Pariparoba e outras piperaceae como novos produtos para comercialização. In: Diegues, A. C. \& Viana, V. M. (org.). Comunidades tradicionais e manejo dos recursos naturais da Mata Atlântica: coletânea de textos presentados no Seminário alternativas de manejo sustentável de recursos naturais do Vale do Ribeira. NUPAUB.

Dutra, R. C., Campos, M. M., Santos, A. R. S. \& Calixto, J. B. (2016). Medicinal plants in Brazil: Pharmacological studies, drug discovery, challenges and perspectives. Pharmacological Research, (112), 4-29.

Ferreira, S. N. \& Sampaio, M. J. A. M. (org.). (2013). Biodiversidade e conhecimentos tradicionais associados: implementação da legislação de acesso e repartição de benefício no Brasil. SBPC.

Homma, A. K. O. (2014). Extrativismo vegetal na Amazônia: história, ecologia, economia e domesticação. Embrapa.

INTERFARMA. (2018). Guia Interfarma 2018. INTERFARMA - Associação da Indústria Farmacêutica de Pesquisa. https://www.interfarma.org.br/guia/guia2018/dados_do_setor\#mercado_farmaceutico_mundial.

IBGE. (2020). Sistema IBGE de Recuperação Automática - SIDRA. IBGE - Instituto Brasileiro de Geografia e Estatística. https://sidra.ibge.gov.br. IBGE. (2018). O Brasil Indígena. Rio de Janeiro. IBGE - Instituto Brasileiro de Geografia e Estatística. https://indigenas.ibge.gov.br/. 
Isaac, G. E. A. (2016). O desenvolvimento sustentável do setor cosmético e o comportamento do consumidor frente aos cosméticos sustentáveis. Dissertação de mestrado, Centro Universitário das Faculdades Associadas de Ensino, Programa de Pós-graduação em Desenvolvimento Sustentável, São João da Boa Vista, SP, Brasil.

Joly, C. A., Scarano, F. R., Bustamante, M., Gadda, T., Metzger, J. P., Seixas, C. S., Ometto, J., Pires, A. P. F., Boesing, A. L., Sousa, F. D. R., Quintão, J. M., Gonçalves, L., Padgurschi, M., Aquino, M. F. S., Castro, P. D. \& Santos, I. de L. (2018). Sumário para tomadores de decisão - $1^{o}$ diagnóstico brasileiro de biodiversidade e serviços ecossistêmicos. Campinas. PBBSE - Plataforma brasileira de biodiversidade e serviços ecossistêmicos. https://www.bpbes.net.br/wpcontent/uploads/2018/11/Sum\%C3\%A1rio-para-Tomadores-de-Decis\%C3\%A3o-BPBES-1.pdf

Kaplan, M. A. C. \& Figueiredo, M. R. (2006). O valor da diversidade química das plantas. In: Garay, I. \& Becker, B. K. (org.). As dimensões humanas da biodiversidade: os desafios de novas relações sociedade-natureza no século XXI. Editora Vozes.

Lakatos, E. M. \& Marconi, M. de A. (2003). Fundamentos da metodologia científica. Atlas.

Miguel, L. M. (2012). Biodiversidade na indústria de cosméticos: contexto internacional e mercado brasileiro. Tese de doutorado, Universidade de São Paulo, Programa de Pós-graduação em Geografia Humana, São Paulo, SP, Brasil.

Milanezi, N. G. \& Barbosa, B. (2013). O exemplo brasileiro no combate à biopirataria. In: Ferreira, S. N. \& Sampaio, M. J. A. M. (org.). Biodiversidade e conhecimentos tradicionais associados: implementação da legislação de acesso e repartição de benefícios no Brasil. SBPC.

OCE. (2018). Perfil Nacional do Brasil. Cambridge. OCE - Observatório da Complexidade Econômica. https://atlas.media.mit.edu/.

OMPI. (2014). Documentação de Conhecimento Medicinal Tradicional. Genebra. OMPI - Organização Mundial de Propriedade Intelectual.

Rampozzo, S. E. \& Corrêa, F. Z. M. (2008). Desmistificando a metodologia científica: guia prático de produção de trabalhos acadêmicos. Habilis.

Shiva, V. (2005). Biodiversidade, direitos de propriedade intelectual e globalização. In: Santos, B. S. (org.). Semear outras soluções: os caminhos da biodiversidade e dos conhecimentos rivais. Civilização Brasileira.

Santilli, J. (2005). Socioambientalismo e novos direitos: proteção jurídica à diversidade biológica e cultural. Editora Peirópolis.

Souza, A. L. G. (2019). O acesso legal aos conhecimentos tradicionais associados à biodiversidade e as repartições dos benefícios advindos das explorações econômicas no Brasil. Tese de Doutorado, Universidade Federal de Sergipe, Programa de Pós-graduação em Ciência da Propriedade Intelectual, São Cristóvão, SE, Brasil.

TCU (2016). Auditoria. Ações de Combate À Biopirataria do Patrimônio Genético da Amazônia. Possibilidade de Melhorias nas Ações de Repressão e de Pesquisa (TC 027.987/2015-9). Brasília. TCU - Tribunal de Contas da União do Estado Brasileiro. https://contratospublicos.com.br/tcu-auditoria-acoes-decombate-a-biopirataria-do-patrimonio-genetico-da-amazonia-possibilidade-de-melhorias-nas-acoes-de-repressao-e-de-pesquisarecomendacoes/jurisprudencia?fbclid=IwAR23J0XLjwaySbMFktrmiNaCC4jjDcB7duRycPtKiH4uq7RVDB0wuQdSVJo.

TEEB. (2012). The Economics of Ecosystems and Biodiversity: Relatório Preliminar TEEB para o setor de negócios brasileiro - sumário executivo 2012. Brasília. CI - Conservação Internacional.

Udry, C., Eidt, J. S., Dias, T. A. B. \& Bustamante, P. G. (2015). Povos indígenas e comunidades tradicionais: uma agenda de pesquisa em construção na Embrapa. In: Udry, C. \& Eidt, J. S. (org.). Conhecimento tradicional: conceitos e marco legal. EMBRAPA. 